\title{
Noninvasive cerebral oxygenation may predict outcome in patients undergoing aortic arch surgery
}

\author{
Gregory W. Fischer, MD, ${ }^{\text {a,b }}$ Hung-Mo Lin, PhD, ${ }^{a}$ Marina Krol, PhD, ${ }^{\text {a }}$ Maria F. Galati, MBA, ${ }^{a}$ Gabriele Di \\ Luozzo, MD, ${ }^{\mathrm{b}}$ Randall B. Griepp, MD, ${ }^{\mathrm{b}}$ and David L. Reich, $\mathrm{MD}^{\mathrm{a}}$
}

\begin{abstract}
Objectives: Surgical repair of the aortic arch remains technically challenging and is associated with considerable morbidity and mortality. Cerebral oximetry is a noninvasive technology that can monitor the regional oxygen saturation of the frontal cortex. We hypothesized that magnitude and duration of decreased intraoperative regional oxygen saturation was associated with postoperative organ dysfunction. Additionally, we sought to identify regional oxygen saturation threshold values that are predictive of organ dysfunction.
\end{abstract}

Methods: The intraoperative regional oxygen saturation values of 30 patients undergoing aortic arch surgery were recorded and analyzed. Postoperative complications were categorized as "major" and "minor." Severe adverse outcome, extubation time, intensive care unit length of stay, and hospital length of stay data were collected and compared with the integrals of regional oxygen saturation and time (area under the threshold) spent beneath predetermined absolute threshold limits.

Results: Twenty subjects underwent hemiarch replacement, and 10 subjects received total aortic arch replacements. There were 30 major and 29 minor complications identified. Sixteen $(53.3 \%)$ patients had at least 1 major complication. Logistic regression showed statistically significant associations between area under the threshold and severe adverse outcome incidence for regional oxygen saturation thresholds of $60 \%(P=.038)$ and $65 \%$ $(P=.025)$. Patients who spent more than 30 minutes under the absolute threshold of $60 \%$ had an extended hospital stay of 4 days leading to an additional cost of $\$ 8300.00$.

Conclusions: Our findings lend evidence to support the association of decreased perioperative cerebral oxygenation values with poor outcomes after aortic arch surgery. (J Thorac Cardiovasc Surg 2011;141:815-21)

Surgical repair of the aortic arch remains technically challenging and is associated with considerable morbidity and mortality. Prolonged cardiopulmonary bypass (CPB) times, embolic risk, and interruption of brain blood flow are integral to these procedures. Consequently, neurologic and neuropsychologic sequelae occur more frequently with aortic arch surgery than with coronary and valvular cardiac surgery; stroke rates have been reported in the range of $6 \%$ to $13 \%,{ }^{1}$ with neuropsychologic impairment being even more frequent. ${ }^{2}$

Near-infrared spectroscopy technology has been used to monitor cerebral oxygenation noninvasively, and these data may be predictive of adverse neurologic outcomes. Murkin and colleagues ${ }^{3}$ monitored near-infrared spectroscopy and targeted therapy to optimize cerebral tissue oxygen saturations $\left(\mathrm{Scto}_{2}\right)$ in patients undergoing coronary artery

\footnotetext{
From the Departments of Anesthesiology ${ }^{\mathrm{a}}$ and Cardiothoracic Surgery, ${ }^{\mathrm{b}}$ Mount Sinai School of Medicine, Mount Sinai Medical Center, New York, NY. Supported by National Institutes of Health grant NS045488.

Disclosures: Authors have nothing to disclose with regard to commercial support.

Received for publication Dec 1, 2009; revisions received May 5, 2010; accepted for publication May 16, 2010; available ahead of print June 25, 2010.

Address for reprints: Gregory W. Fischer, MD, Department of Anesthesiology \& Cardiothoracic Surgery, One Gustave L. Levy Place, Box 1010, Mount Sinai Medical Center, New York, NY 10029 (E-mail: Gregory.Fischer@mountsinai.org). 0022-5223/\$36.00

Copyright $(c) 2011$ by The American Association for Thoracic Surgery doi:10.1016/j.jtcvs.2010.05.017
}

bypass grafting. They found that a composite measure of organ dysfunction was substantially improved in the treatment group where goal-directed therapy aimed to maintain the $\mathrm{SctO}_{2}$ values within $25 \%$ of the preinduction baseline.

More recently developed near-infrared spectroscopy technology using a 4-wavelength interrogation of brain tissue has been validated as a monitor of absolute $\mathrm{Scto}_{2} \cdot{ }^{4}$ A potential advantage of absolute brain tissue oxygenation is that threshold values may be more strongly associated with adverse outcomes than trends. We hypothesized that magnitude and duration of decreased intraoperative $\mathrm{SctO}_{2}$ was associated with postoperative organ dysfunction after aortic arch surgery. Additionally, we sought to identify $\mathrm{SctO}_{2}$ threshold values that are predictive of organ dysfunction.

\section{METHODS}

With institutional review board approval and informed consent, 31 patients undergoing elective thoracic aortic surgery with deep hypothermic circulatory arrest (DHCA), with or without anterograde selective cerebral perfusion (SCP), were monitored intraoperatively using the FORESIGHT cerebral oximeter (CAS Medical Systems, Branford, Conn) at our institution from 2005 to 2008 (Figure 1).

After the induction of general anesthesia, 2 sensors were placed on the subjects' foreheads bilaterally for continuous monitoring of $\mathrm{SctO}_{2} . \mathrm{SctO}_{2}$ values were recorded every 2 seconds starting after induction of anesthesia until the end of surgery. Scto ${ }_{2}$ minutes and the area under the threshold (AUT) spent beneath the absolute threshold limits of $50 \%, 55 \%, 60 \%$, and $65 \%$ were computed for both left and right sensors during the entire 


$$
\begin{aligned}
& \text { Abbreviations and Acronyms } \\
& \text { AUT = area under the threshold } \\
& \text { CPB }=\text { cardiopulmonary bypass } \\
& \text { DHCA }=\text { deep hypothermic circulatory arrest } \\
& \text { ICU }=\text { intensive care unit } \\
& \text { LOS }=\text { length of stay } \\
& \text { SAO }=\text { severe adverse outcome } \\
& \text { SCP }=\text { selective cerebral perfusion } \\
& \text { Scto } 2 \text { = cerebral tissue oxygen saturation } \\
& \text { TUT }=\text { time under the threshold }
\end{aligned}
$$

intraoperative period. Figure 2 demonstrates the AUT. The AUT was calculated on the basis of this formula:

$$
\begin{aligned}
A U T(\text { present })= & A U T(\text { past })+\left(\mathrm{SctO}_{2}\right. \text { threshold } \\
& \left.-\mathrm{SctO}_{2} \text { value }\right) \times \text { sample rate }
\end{aligned}
$$

Complications were categorized as "major" and "minor." Major complications were defined as death, stroke with persisting neurologic deficits at time of discharge, new onset of impaired myocardial function (defined as decrease of left ventricular ejection fraction $>20 \%$ from preoperative baseline), respiratory failure (defined as ventilator dependency $>3$ days or reintubation), sepsis, delirium, new onset renal failure (defined as requiring renal replacement therapy after surgery), gastrointestinal complication (ischemia or hemorrhage requiring an intervention), and severe volume overload (defined as weighing $>20 \mathrm{~kg}$ when compared with preoperative weight). Minor or no complications included new onset of atrial fibrillation, minor volume overload (defined as 10-20 kg over preoperative weight), phlebitis, or no complication.

Postoperative complications, extubation time, intensive care unit (ICU) length of stay (LOS), and hospital LOS data were collected and compared with $\mathrm{Scto}_{2}$ data and DHCA time.

\section{Anesthesia and Monitoring}

After the application of standard American Society of Anesthesiologists monitors, general anesthesia was induced in all patients with etomidate, fentanyl, and midazolam. Neuromuscular blockade was achieved with vecuronium or cisatracurium before tracheal intubation. A balanced anesthetic technique was used for maintenance, consisting of isoflurane $(0.6 \%-1.5 \%$ end-tidal concentration), fentanyl, vecuronium or cisatracurium, and midazolam. All patients were mechanically ventilated with an inspired oxygen fraction of $100 \%$ in a pressure-regulated volume-controlled mode so as to maintain the $\mathrm{PaCO}_{2}$ at 35 to $45 \mathrm{~mm} \mathrm{Hg}$. Vital signs and depth of anesthesia were monitored and controlled in accordance with best clinical practice at the discretion of the attending anesthesiologist. All patients were transferred after the end of surgery, still under the influence of general anesthesia, to the cardiothoracic ICU for further clinical management.

The following monitors were placed: a left radial arterial catheter, a pulmonary artery catheter inserted via the right internal jugular vein, a 20gauge jugular bulb catheter for intermittent sampling of jugular venous blood, and a urinary bladder catheter with an integrated temperature thermistor (to measure core temperature). Transesophageal echocardiography was performed routinely in all patients.

A glucocorticoid bolus after induction of anesthesia was administered to all patients according to an institutional protocol (methylprednisone $30 \mathrm{mg} /$ $\mathrm{kg}$ ). All patients received either epsilon-aminocaproic acid or aprotinin. Epsilon-aminocaproic acid was administered as a $150 \mathrm{mg} / \mathrm{kg}$ bolus, followed by an infusion $\left(15 \mathrm{mg} \cdot \mathrm{kg}^{-1} \cdot \mathrm{h}^{-1}\right)$ for the duration of the case. Aprotinin was administered according to the Hammersmith protocol. ${ }^{5}$
Subjects remained in the supine position during surgery, allowing for only positional changes to facilitate surgical exposure. There was no alteration in surgical technique or routine clinical monitoring.

\section{Surgical Technique}

All patients received right axillary cannulation as described by Strauch and associates. ${ }^{6}$ After sternotomy and dissection of the heart and great vessels, a 2-stage cannula was placed into the right atrium for venous drainage.

Two subsets of patients requiring elective thoracic aortic arch surgery were included in this study. The first population required replacement of the entire aortic arch. The technique used is described in detail by Spielvogel and colleagues. ${ }^{7}$ In brief, after $\mathrm{CPB}$ is commenced, patients are cooled to a nasopharyngeal temperature of $12^{\circ} \mathrm{C}$ to $15^{\circ} \mathrm{C}$ with alpha-stat management. Ischemic DHCA is commenced once the aforementioned criteria are fulfilled. During circulatory arrest, a trifurcated graft is sewn to the head vessels. Once all 3 anastomoses are completed, the graft is deaired and the proximal end clamped. Via the right axillary artery, antegrade SCP is started $(10 \mathrm{~mL} / \mathrm{kg}$ ideal body weight per minute) after 15 to 45 minutes of ischemic DHCA. During SCP a tube graft is used to connect the nondiseased portion of the ascending aorta with the proximal end of the descending aorta. Subsequently, the trifurcated graft is sewn to the aortic tube graft. After meticulous deairing, total body perfusion is commenced and the patient is rewarmed.

The other group consisted of patients requiring repair of the ascending aorta with a beveled suture line at the arch (hemiarch procedure). This technique is described by Etz and collegues in detail. ${ }^{8}$ In brief, the CPB technique and temperature management on $\mathrm{CPB}$ are identical to those described for total aortic arch replacement. The proximal anastomosis is performed with the aorta crossclamped. Once the anastomosis is completed and all arrest criteria are fulfilled (temperature $12^{\circ} \mathrm{C}-15^{\circ} \mathrm{C}$, jugular venous oxygen saturation $>94 \%$, and a minimal cooling time of 45 minutes), circulatory arrest is commenced for suturing of the distal anastomosis. Once completed, total body circulation is resumed and the patient is rewarmed. No SCP is required for this technique.

\section{DHCA}

The technique of DHCA used at our institution was constant throughout the study and has been described in detail previously. A minimum of 45 minutes of cooling was allowed before arresting the circulation. Adequate cerebral cooling was ensured in all cases by a jugular venous saturation of greater than $94 \%$ and a nasopharyngeal temperature of $12^{\circ} \mathrm{C}$ to $15^{\circ} \mathrm{C}$. In all patients in whom more than 20 minutes of DHCA was anticipated or SCP was used, the head was packed circumferentially in ice.

Perfusion warming was carried out at the end of the procedure, with the gradient between the esophageal and blood temperatures maintained at less than $10^{\circ} \mathrm{C}$. Warming was maintained until the esophageal temperature reached $35^{\circ} \mathrm{C}$ and the bladder temperature was greater than $32^{\circ} \mathrm{C}$. Warming was usually accomplished in 1 hour of perfusion.

\section{Perfusion}

Once on $\mathrm{CPB}$, flow rates of 2.0 to $2.6 \mathrm{~L} \cdot \mathrm{min}^{-1} \cdot \mathrm{m}^{-2}$ were maintained, adjusted to the overall metabolic demand of the individual patient. Lactate and mixed venous oxygenation were serially followed. Myocardial protection was provided with cold antegrade blood cardioplegia. In patients with severe coronary disease, retrograde blood cardioplegia was added. Cardioplegic solution was administered every 20 to 30 minutes during periods of myocardial ischemia. Temperature management of the patient was directed by the attending surgeon. All cooling was performed with alpha-stat management. CPB circuits were equipped with a $40-\mu \mathrm{m}$ arterial line filter, a non-surface modified membrane oxygenator, and an integrated venous and cardiotomy reservoir, having a prime volume of $1600 \mathrm{~mL}$. The prime consisted of PlasmaLyte solution (Baxter Healthcare Corporation, Deerfield, Ill), $50 \mathrm{mEq} \mathrm{NaHCO} 3,12.5 \mathrm{~g}$ mannitol, and 10,000 $\mathrm{U}$ of unfractionated heparin. 


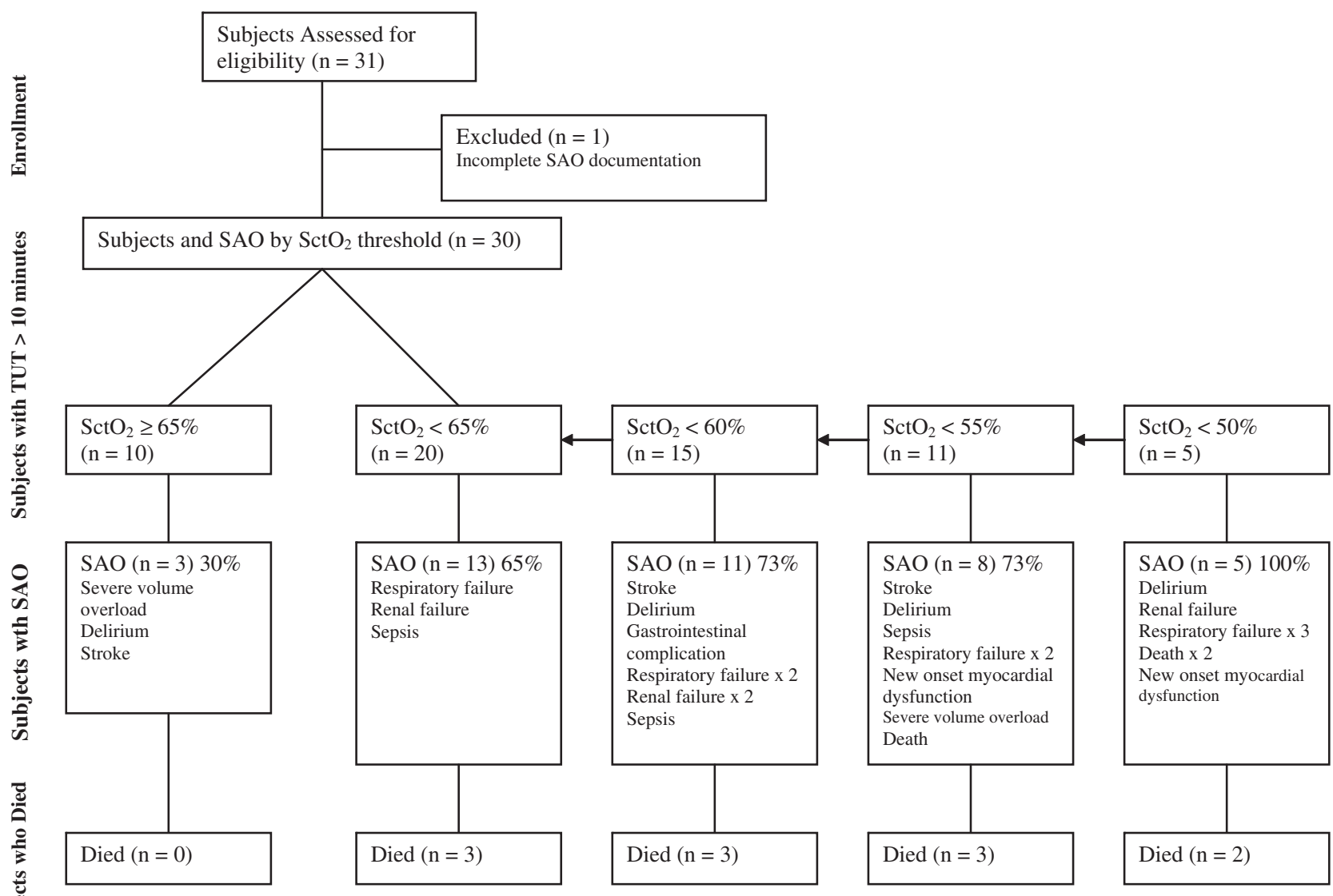

IGURE 1. CONSORT diagram of 31 patients undergoing elective thoracic aortic surgery with deep hypothermic circulatory arrest (DHCA). SAO, Severe adverse outcome; $\mathrm{SctO}_{2}$, cerebral tissue oxygen saturation.

\section{Statistics}

For 2 group comparisons, Fisher's exact tests were used for categorical variables and either the Student $t$ tests or nonparametric Wilcoxon tests for continuous variables, as appropriate. Age-adjusted logistic regression was used to assess the association between exposure time and severe adverse

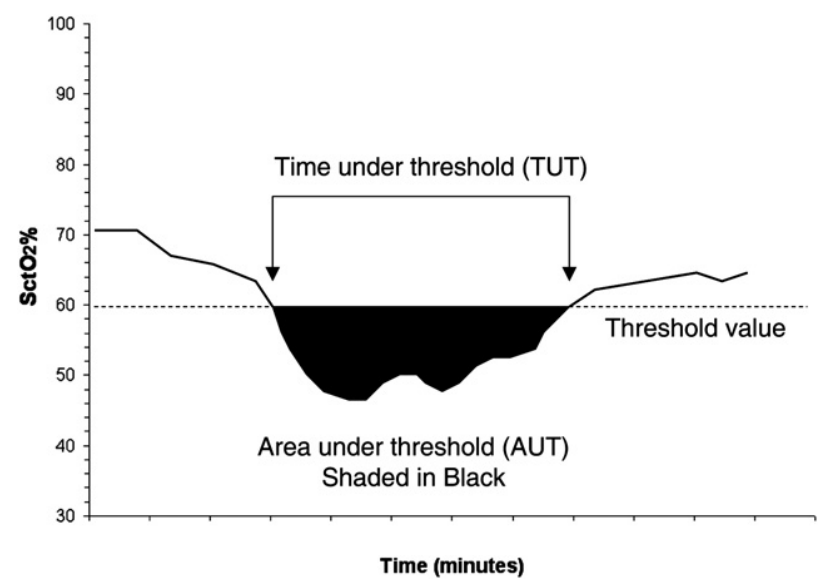

FIGURE 2. Area under the threshold $(A U T)$. $A U T$ (present) $=A U T$ (past) + $\left(\mathrm{SctO}_{2}\right.$ Threshold $-\mathrm{Scto}_{2}$ value $) \times$ sample rate. $\mathrm{Scto}_{2}$, Cerebral tissue oxygen saturation. outcome (SAO), which was defined as having at least 1 major complication after surgery. Effects of exposure time are expressed in terms of odds ratios. Because of the small sample size, profile-likelihood confidence intervals were used. The $c$-statistic, also known as the area under the receiver operating characteristic curve, was also reported to indicate the predictability of obtaining a SAO, using age and exposure time as predictors. Owing to the limited number of SAOs, no other covariates were considered in the model. Spearman correlation coefficients were used to evaluate the strength of associations between exposure time and area under the $\mathrm{Scto}_{2}$ threshold for extubation, ICU time, and total hospital LOS time. We performed sensitivity analyses to assess how deaths affect the associations between hospital outcomes and $\mathrm{Scto}_{2}$. The assumption here is that hospital LOS would have been longer than the observed if death did not occur. The first analysis assigned the maximum LOS in the study (=102 days) to the extubation/ ICU/hospital LOS days for all 3 deaths. The second analysis assigned the median hospital LOS for the SAO group (=13 days) to the extubation/ ICU/hospital LOS days for the 1 patient who died before day 13 . The last analysis was based on the original data. All statistical analyses were carried out using SAS (SAS Institute, Inc, Cary NC). The authors had full access to the data.

\section{RESULTS}

Complete postoperative data were available for 30 patients. One patient was excluded from the study owing to insufficient postoperative documentation. The demographics 
TABLE 1. Population demographics and intraoperative and postoperative data

\begin{tabular}{|c|c|}
\hline Variable & Mean (SD) or median (IQR) \\
\hline Weight (kg) & $86.0(23.5)$ \\
\hline Height $(\mathrm{cm})$ & $176.4(9.1)$ \\
\hline Body surface area $\left(\mathrm{m}^{2}\right)$ & $2.0(0.3)$ \\
\hline Age (y) & $68.7(12.1)$ \\
\hline Male $(\%)$ & $73 \%$ \\
\hline White $(\%)$ & $83 \%$ \\
\hline Prearrest hematocrit $(\%)$ & $26.2(4.2)$ \\
\hline Temperature at arrest $\left({ }^{\circ} \mathrm{C}\right)$ & $13.6(1.9)$ \\
\hline DHCA (min) & $24.7(8.0)$ \\
\hline $\mathrm{pH}$ & $7.4(0.1)$ \\
\hline $\mathrm{PaCO}_{2}(\mathrm{~mm} \mathrm{Hg})$ & $43.2(6.9)$ \\
\hline $\mathrm{PaO}_{2}(\mathrm{~mm} \mathrm{Hg})^{*}$ & $318.5(264.0,379.0)$ \\
\hline Extubation time $(\mathrm{d}) *$ & $1.5(1,4.0)$ \\
\hline $\operatorname{ICU}$ stay $(\mathrm{d})^{*}$ & $4.0(3.0,8.0)$ \\
\hline Length of stay $(d)^{*}$ & $10.0(7.0,14.0)$ \\
\hline
\end{tabular}

$S D$, Standard deviation; $I Q R$, interquartile range, which is the range between 25 th and 75th percentiles; $D H C A$, deep hypothermic circulatory arrest; $I C U$, intensive care unit. *Median and IQR were presented when data were not normally distributed.

and intraoperative and postoperative information for the 30 patients are displayed in Table 1 . Twenty subjects underwent replacement of the ascending aorta including hemiarch replacement, and 10 subjects received total aortic arch replacements. Figure 3 demonstrates the entire perioperative course of $\mathrm{Scto}_{2}$. Only 21 patients had a plateau temperature at $20^{\circ} \mathrm{C}$ before cooling to arrest temperature. The other 9 patients were cooled directly to arrest temperature. Among the 30 patients, 30 major and 29 minor complications were identified (Table 2). Sixteen (53.3\%) patients had at least 1 major complication, $8(26.6 \%)$ had at least 1 minor complication, and $6(20 \%)$ had no complications reported. For the purpose of analysis, we defined a SAO as having 1 or more major postoperative complications. No statistically significant differences were found between those with and without a SAO for age, gender, height, prearrest hematocrit, temperature at the time of $\mathrm{DHCA}, \mathrm{pH}$, and $\mathrm{PaCO}_{2}$. Patients having a SAO weighed less (mean $\pm \mathrm{SD}, 77.8 \pm 17.0 \mathrm{~kg}$ for SAO vs $95.4 \pm 26.8 \mathrm{~kg}$ for non-SAO; difference [95\% confidence interval, $17.5 \mathrm{~kg}(0.3-35.8 \mathrm{~kg}) ; P=.047])$ and had a smaller body surface area $\left(1.9 \pm 0.2 \mathrm{~m}^{2}\right.$ for SAO vs $2.1 \pm 0.3 \mathrm{~m}^{2}$ for non-SAO; difference [95\% confidence interval]: $\left.\left.0.2(0.0-0.4) \mathrm{m}^{2} ; P=0.046\right]\right)$.

Eight $(27 \%)$ patients did not have $\mathrm{Scto}_{2}$ values less than $65 \%$. Each of the remaining 22 patients who had an $\mathrm{Scto}_{2}$ of less than $65 \%$ also had a decline in $\mathrm{Scto}_{2}$ of less than $60 \%$. Nineteen patients had an $\mathrm{Scto}_{2}$ of less than $55 \%$, and 12 subjects had an $\mathrm{Scto}_{2}$ of $50 \%$. The integrals of $\mathrm{SctO}_{2}$ under specific thresholds (AUT) over time are presented in Table 3. The median exposure times for $\mathrm{Scto}_{2}$ less than $50 \%, 55 \%, 60 \%$, and $65 \%$ were $4,12,29$, and 128 minutes, respectively. In addition, among the 19 patients who had an $\mathrm{Scto}_{2}$ of less than $55 \%$, the median times

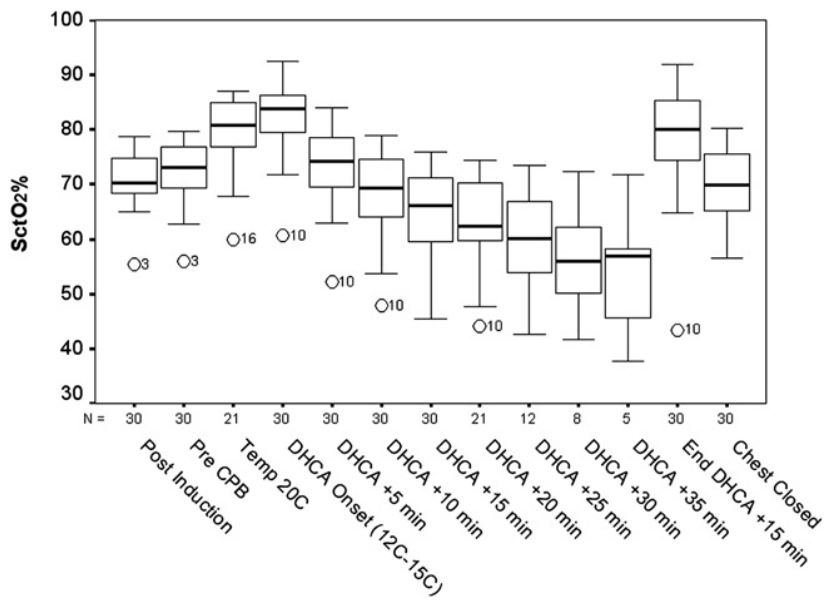

FIGURE 3. Temporal pattern of $\mathrm{Scto}_{2}$ values during the perioperative course. Summary box plot is based on the median, quartiles, and extreme $\mathrm{SctO}_{2}$ values. The box represents the interquartile range, which contains $50 \%$ of $\mathrm{Scto}_{2}$ values. The whiskers are lines that extend from the box to the highest and lowest $\mathrm{Scto}_{2}$ values, excluding outliers. A line across the box indicates the median. The $\mathrm{Scto}_{2}$ values reported in the box plot are the mean of left and right forehead cerebral oximetry sensor values. Key to events: Post Induction, $\mathrm{Scto}_{2}$ right after sensors placed on head during post induction; Pre CPB, $\mathrm{Scto}_{2} 2$ minutes before onset of CPB; Temp20C, $\mathrm{Scto}_{2}$ plateau for those subjects with initial hypothermia to $20^{\circ} \mathrm{C} ; \mathrm{DHCA}$ Onset, maximum $\mathrm{Scto}_{2}$ value during deep hypothermia just before DHCA onset; $\mathrm{DHCA}+5 \mathrm{~min}, \mathrm{Scto}_{2} 5$ minutes after onset of DHCA; $\mathrm{DHCA}+10$ $\mathrm{min}, \mathrm{Scto}_{2} 10$ minutes after onset of DHCA; $D H C A+15 \mathrm{~min}$, $\mathrm{Scto}_{2} 15 \mathrm{~min}-$ utes after onset of DHCA; $D H C A+20$ min, Scto $_{2} 20$ minutes after onset of DHCA; $D H C A+25$ min, Scto $_{2} 25$ minutes after onset of DHCA; $D H C A+30$ min, $\mathrm{Scto}_{2} 30$ minutes after onset of DHCA; $\mathrm{DHCA}+35 \mathrm{~min}$, $\mathrm{Scto}_{2} 35 \mathrm{~min}-$ utes after onset of DHCA; End DHCA +15 min, Scto $_{2} 15$ minutes after DHCA; Chest Closed, $\mathrm{SctO}_{2}$ right after end of surgery. $N$ is the number of subjects out of 30 that had each of the events; $\mathrm{SctO}_{2}$, Cerebral tissue oxygen saturation.

during which $\mathrm{Scto}_{2}$ fell in the ranges of $60 \%$ to $65 \%, 55 \%$ to $60 \%$, and $50 \%$ to $55 \%$ were 50,25 , and 9 minutes, respectively. Although only $33 \%$ of patients who did not desaturate beneath an $\mathrm{Scto}_{2}$ of $65 \%$ for more than 10 minutes had a SAO, this number increased dramatically to $67 \%$ for those subjects who did. All patients with $\mathrm{SctO}_{2}$ values beneath $50 \%$ for at least 10 minutes had a SAO.

Logistic regression was used to investigate the relationship between $\mathrm{SAO}$ and $\mathrm{Scto}_{2}$ exposure time under a given threshold (TUT), controlling for age (Table 4). There were statistically significant associations between TUT and SAO incidence for $\mathrm{Scto}_{2}$ thresholds of $60 \%(P=.038)$ and $65 \%(P=.025)$. Figure 4 demonstrates the odds ratios with $95 \%$ confidence intervals for SAO for incremental exposure time to $\mathrm{SctO}_{2}$ values under specific thresholds. For every $5 \%$ decrease in the absolute $\mathrm{Scto}_{2}$ threshold, the incremental exposure time to achieve a given odds ratio (for SAO) decreased by half for $\mathrm{SctO}_{2}$ thresholds between $55 \%$ and $65 \%$. The predictive values ( $c$-statistic) of TUT for 
TABLE 2. Complications

\begin{tabular}{lc}
\hline \multicolumn{1}{c}{ Major complications } & Subjects with complication \\
\hline Death & $3(10 \%)$ \\
Stroke & $3(10 \%)$ \\
New-onset myocardial dysfunction & $2(6.7 \%)$ \\
Respiratory failure & $8(26.7 \%)$ \\
Sepsis & $3(10 \%)$ \\
Delirium & $4(13.4 \%)$ \\
Renal failure requiring dialysis & $4(13.4 \%)$ \\
GI complications requiring intervention & $1(3.3 \%)$ \\
Severe volume overload, edema & $2(6.7 \%)$ \\
Minor or no complication & \\
Atrial fibrillation & $13(44.8 \%)$ \\
Minor volume overload & $7(24.1 \%)$ \\
Phlebitis & $3(10.3 \%)$ \\
None & $6(20.7 \%)$ \\
\hline
\end{tabular}

SAO (controlling for age) were $0.77,0.81$, and 0.83 for $\mathrm{SctO}_{2}$ thresholds of 55,60 , and $65 \%$, respectively. Older age demonstrated a marginally significant trend toward predicting SAO $(0.05<P<.1$ for all 3 threshold models $)$. The odds of having a SAO roughly doubled for every 10 years increase in age.

On the basis of these findings, we further explored the relationship between duration of exposure time and AUT and hospital course. We considered 3 analyses to take into account deaths in different ways (see Methods section for details). The assumption is that hospital LOS would have been longer than that observed if death had not occurred. Overall, Spearman correlations showed a positive relationship between time and AUT for extubation time, ICU stay, and hospital LOS (Table 5). In particular, in all 3 analyses, patients with greater duration of low $\mathrm{SctO}_{2}$ and showing greater integrals of low $\mathrm{SctO}_{2}$ over time for the $\mathrm{Scto}_{2}$ threshold values of $65 \%$ and $60 \%$ were significantly more likely to have prolonged postoperative mechanical ventilation and longer LOS in the ICU. The hospital LOS demonstrated the same trend as extubation time and ICU LOS, but lost its significance when original data were used. The $\mathrm{SctO}_{2}$ threshold values of $55 \%$ showed slightly lower correlations, as a result of fewer patients having time points spent below this threshold (thus, a big cluster of zeros for time and AUT).

Finally, we explored the financial burden posed on our institution as a direct result of prolonged ICU and hospital

TABLE 3. Exposure time and area under $\mathrm{Scto}_{2}$ thresholds

\begin{tabular}{lccc}
\hline & & \multicolumn{2}{c}{ Median (range) } \\
\cline { 3 - 4 } Scto $_{2}(\%)$ & N (\%) & Time (min) & AUT (\% - min) \\
\hline Scto $_{2}<50 \%$ & $12(40 \%)$ & $4.0(0.1,263.0)$ & $6.7(0.2,1973.8)$ \\
Scto $_{2}<55 \%$ & $19(63 \%)$ & $11.7(0.2,363.1)$ & $29.0(0.1,3575.4)$ \\
Scto $_{2}<60 \%$ & $22(73 \%)$ & $28.5(0.7,425.0)$ & $117.6(1.1,5544.9)$ \\
Scto $_{2}<65 \%$ & $22(73 \%)$ & $128.1(2.7,486.9)$ & $382.9(14.3,7829.4)$ \\
\hline
\end{tabular}

$\mathrm{SctO}_{2}$, Cerebral tissue oxygen saturation; $A U T$, area under threshold.
TABLE 4. Logistic regression models for the relationships between SAO and time under $\mathrm{Scto}_{2}$ threshold (TUT) of 55\%, 60\% and $65 \%$, controlling for age

\begin{tabular}{llccc}
\hline Model & Parameter & $\begin{array}{c}\text { Coefficient } \\
\text { estimate }\end{array}$ & $\begin{array}{c}\text { Standard } \\
\text { error }\end{array}$ & $\boldsymbol{P}$ value \\
\hline $\mathrm{SctO}_{2}<55 \%$ & Intercept & -4.898 & 2.795 & .080 \\
& TUT (min) & 0.061 & 0.039 & .117 \\
& Age (y) & 0.063 & 0.038 & .098 \\
$\mathrm{Scto}_{2}<60 \%$ & Intercept & -6.047 & 3.116 & .052 \\
& TUT (min) & 0.034 & 0.016 & .038 \\
& Age(y) & 0.074 & 0.042 & .077 \\
$\mathrm{SctO}_{2}<65 \%$ & Intercept & -5.693 & 3.045 & .063 \\
& TUT (min) & 0.016 & 0.007 & .025 \\
& Age (y) & 0.067 & 0.040 & .096 \\
\hline
\end{tabular}

The probability of SAO is $\operatorname{Pr}(\mathrm{SAO})=\frac{\exp (y)}{1+\exp (v)}$, where $\exp ()$ is the exponential function, and $y$ is calculated using the $\beta$-coefficients above. For example, for a 70 year-old patient who had 30 minutes of $\mathrm{Scto}_{2}$ under $65 \%, y=-5.693+$ $0.016 \times$ TUT $+0.067 \times$ age $=-5.693+0.016 \times 30+0.067 \times 70=-0.523$. Then $\operatorname{Pr}(\mathrm{SAO})=0.37$. SAO, Severe adverse outcome; $\mathrm{Scto}_{2}$, cerebral tissue oxygen saturation.

LOS. For the purpose of illustration, we applied the predictive model to patients who spent more than 30 minutes beneath the $\mathrm{SctO}_{2}$ threshold value of $60 \%$ as opposed to patients who did not. Median LOS was predicted to be 3 days longer (6 vs 3 ) in the ICU, and the total hospital stay was 4 days longer (13 vs 9), of which 2 days were attributable to ICU stay and 1 to non-ICU stay. The total cost of this additional stay was calculated to be $\$ 8300.00$ at our institution using hospital financial estimates of cardiac surgical inpatient costs.

\section{DISCUSSION}

Decreased $\mathrm{Scto}_{2}$ values were associated with major complications, prolonged postoperative mechanical ventilation, and prolonged ICU and hospital LOS. Both the nadir of $\mathrm{Scto}_{2}$ and the integral of low $\mathrm{Scto}_{2}$ over time were associated with severe adverse outcomes. Each additional decade of life was associated with doubled risk of SAO.

The current study is not the first to demonstrate associations among cerebral oximetry values and clinical outcomes during the perioperative period. Recent work by Murkin and colleagues ${ }^{3}$ demonstrated reduced LOS in patients undergoing coronary artery bypass grafting when low $\mathrm{Scto}_{2}$ episodes were treated with a preset protocol. Slater and colleagues ${ }^{9}$ found that patients with prolonged low $\mathrm{Scto}_{2}$ undergoing coronary artery bypass grafting had a higher incidence of early postoperative neurocognitive dysfunction and prolonged hospital LOS. Casati and colleagues ${ }^{10}$ showed a shorter length of postanesthesia care unit and hospital LOS in abdominal surgery when patients were actively treated to maintain $\mathrm{Scto}_{2}$ greater than $75 \%$ of the baseline values using a preset algorithm. Previous studies have also identified the geriatric age group as an independent risk factor for early mortality in complex cardiac 

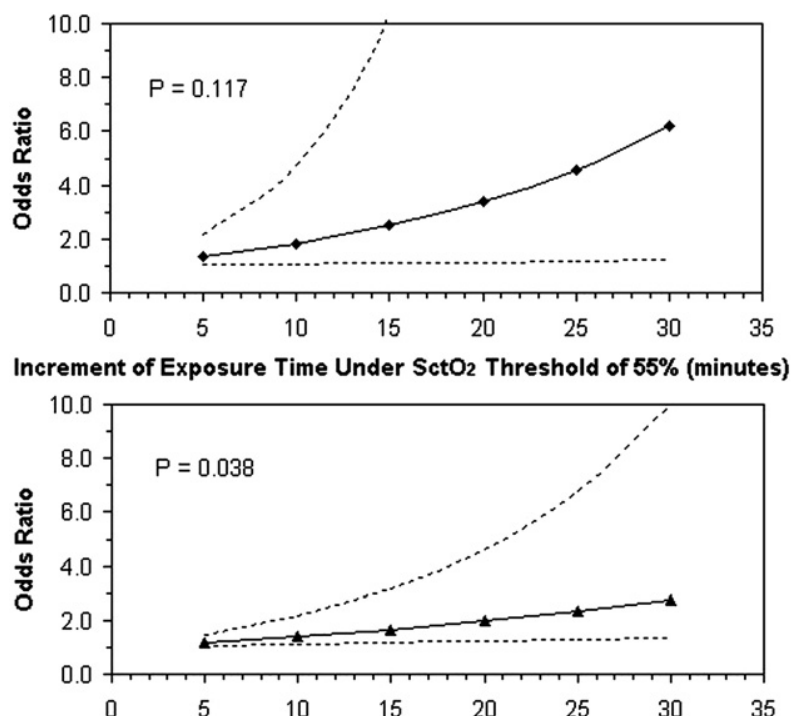

Increment of Exposure Time Under SctO2 Threshold of $60 \%$ (minutes)

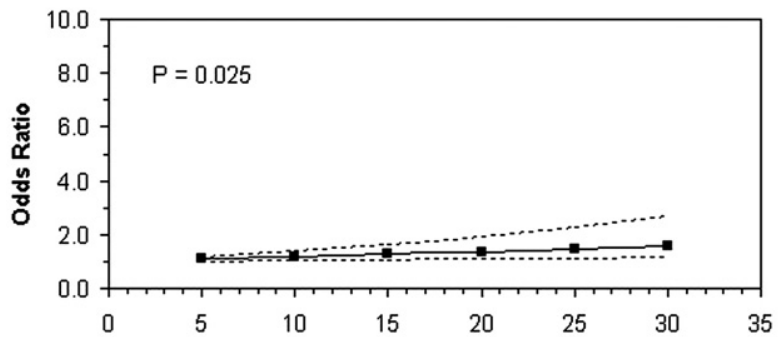

Increment of Exposure Time Under SctO2 Threshold of $65 \%$ (minutes)

FIGURE 4. Odds ratios for $\mathrm{SAO}$ for incremental exposure time to $\mathrm{SctO}_{2}$ values under specific thresholds. For every $5 \%$ decrease in the absolute $\mathrm{SctO}_{2}$ threshold, the incremental exposure time to achieve a given odds ratio (for $\mathrm{SAO}$ ) decreased by half for $\mathrm{Scto}_{2}$ thresholds between $55 \%$ and $65 \%$. $C$-statistics of time under the threshold for SAO were $0.77,0.81$ and 0.83 and for $\mathrm{SctO}_{2}$ thresholds of 55, 60, and 65\%, respectively. The odds of having a SAO roughly doubled for every 10 years' increase in age. SAO, Severe adverse outcome; $\mathrm{SctO}_{2}$, cerebral tissue oxygen saturation.

surgery. ${ }^{11,12}$ This is consistent with the general finding that advanced age is associated with loss of end-organ reserve. $^{13}$

This was a prospective observational study. Although statistically significant associations were present, it is unknown whether interventions to increase $\mathrm{Scto}_{2}$ would have averted adverse outcomes. Additionally, perioperative management changes over time. One example in the current study is that aprotinin was withdrawn from clinical practice during patient enrollment, and the small number of patients does not permit analysis of this variable. This study enrolled only patients presenting for aortic arch surgery, and $\mathrm{Scto}_{2}$ was monitored only during the intraoperative period.

\section{The Brain as a Sentinel Organ}

The current study and the ones cited herein demonstrate an evolution in the interpretation of $\mathrm{Scto}_{2}$ data. Although
TABLE 5. Spearman correlation coefficients $\left(r_{s}\right)$ for $\mathrm{Scto}_{2}$ thresholds and postoperative hospital outcomes

\begin{tabular}{|c|c|c|c|c|c|c|}
\hline \multirow[b]{2}{*}{$\operatorname{Scto}_{2}(\%)$} & \multicolumn{2}{|c|}{ Extubation time } & \multicolumn{2}{|c|}{ ICU stay } & \multicolumn{2}{|c|}{ Hospital LOS } \\
\hline & $r_{s}$ & $\begin{array}{c}P \\
\text { value }\end{array}$ & $r_{s}$ & $P$ value & $r_{s}$ & $\begin{array}{c}P \\
\text { value }\end{array}$ \\
\hline \multirow[t]{3}{*}{$<65 \%(\min )$} & $0.53^{*, 1}$ & .002 & $0.58 *$ & $<.001$ & $0.49 *$ & .006 \\
\hline & $0.53^{*, 1}$ & .002 & $0.57 *$ & $<.001$ & $0.41 *$ & .024 \\
\hline & $0.51^{*, 1}$ & .004 & $0.51^{*}$ & .004 & 0.27 & .149 \\
\hline \multirow[t]{3}{*}{$<60 \%(\min )$} & $0.48^{*}$ & .008 & $0.50 *$ & .005 & $0.44^{*}$ & .015 \\
\hline & $0.47 *$ & .008 & $0.49 *$ & .006 & $0.37 *$ & .046 \\
\hline & $0.45^{*}$ & .013 & $0.42 *$ & .020 & 0.23 & .222 \\
\hline \multirow[t]{3}{*}{$<55 \%(\min )$} & $0.35 \dagger$ & .057 & $0.43^{*}$ & .019 & $0.40 *$ & .027 \\
\hline & $0.35 \dagger$ & .059 & $0.42 *$ & .022 & $0.34 \dagger$ & .070 \\
\hline & $0.32 \dagger$ & .084 & $0.34 \dagger$ & .065 & 0.20 & .300 \\
\hline \multirow[t]{3}{*}{$<65 \%$ AUT $(\%-\min )$} & $0.50 *$ & .005 & $0.52 *$ & .003 & $0.45^{*}$ & .013 \\
\hline & $0.50 *$ & .005 & $0.51^{*}$ & .004 & $0.38^{*}$ & .041 \\
\hline & $0.47 *$ & .008 & $0.44 *$ & .015 & 0.24 & .207 \\
\hline \multirow[t]{3}{*}{$<60 \%$ AUT $(\%-\mathrm{min})$} & $0.41^{*}$ & .024 & $0.46^{*}$ & .010 & $0.39 *$ & .034 \\
\hline & $0.41 *$ & .024 & $0.45^{*}$ & .013 & $0.31 \dagger$ & .091 \\
\hline & $0.38 *$ & .037 & $0.38 *$ & .040 & 0.18 & .346 \\
\hline \multirow[t]{3}{*}{$<55 \%$ AUT $(\%-\mathrm{min})$} & $0.35 \dagger$ & .058 & $0.42^{*}$ & .020 & $0.39^{*}$ & .031 \\
\hline & $0.35 \dagger$ & .060 & $0.41^{*}$ & .024 & $0.32 \dagger$ & .090 \\
\hline & $0.32 \dagger$ & .085 & $0.34 \dagger$ & .069 & 0.17 & .350 \\
\hline
\end{tabular}

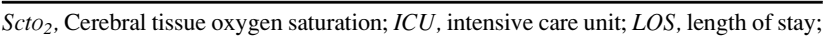
$A U T$, area under threshold; $S A O$, severe adverse outcome. ${ }^{*} P$ value $<.05 \dagger P$ value $<0.1$ (2-tailed). ${ }^{1}$ The study had 3 patients who died; all had SAO and died in the ICU while extubated. Their hospital LOSs were 4, 13 and 102 days, respectively. We performed sensitivity analyses to assess how deaths affect the associations between hospital outcomes and $\mathrm{Scto}_{2}$. The assumption here is that hospital LOS would have been longer than the observed if death did not occur. The first row of the spearman correlations were calculated by assigning 102 days (maximum LOS in the study) to the exbubation/ICU/hospital LOS days for all 3 deaths. In the second row the Spearman correlations were calculated by assigning 13 days (median hospital LOS for the SAO group) to the exbubation/ICU/hospital LOS days for the patient who died on day 4. In the last row the correlations were based on the original data.

investigators were focused originally on the brain and cerebral outcomes, the emerging hypothesis is that $\mathrm{Scto}_{2}$ monitoring may be an index of overall organ perfusion and injury. Our finding that a statistically significant model using $\mathrm{SctO}_{2}$ data predicted ICU and hospital LOS underscores this point and suggests that future studies may investigate the cost-effectiveness of this form of monitoring and intervention.

It is too early to recommend specific target $\mathrm{SctO}_{2}$ values that should be maintained in different clinical settings. On a very preliminary basis, using the technology in this study in the clinical setting of thoracic aortic surgery, we believe that an $\mathrm{SctO}_{2}$ of $60 \%$ to $65 \%$ could represent this threshold value.

In summary, the current study lends further evidence to support the association of decreased perioperative cerebral oxygenation values with poor outcomes. The preliminary finding that absolute threshold values are predictive of adverse outcomes suggests that future investigations should follow the Murkin model of prospective interventional trials that assess general perioperative outcomes. 


\section{References}

1. Gega A, Rizzo JA, Johnson MH, Tranquilli M, Farkas EA, Elefteriades JA. Straight deep hypothermic arrest: experience in 394 patients supports its effectiveness as a sole means of brain preservation. Ann Thorac Surg. 2007;84:759-66.

2. Reich DL, Uysal S, Sliwinski M, Ergin MA, Kahn RA, Konstadt SN, et al. Neuropsychologic outcome after deep hypothermic circulatory arrest in adults. J Thorac Cardiovasc Surg. 1999;117:156-63.

3. Murkin JM, Adams SJ, Novick RJ, Quantz M, Bainbridge D, Iglesias I, et al. Monitoring brain oxygen saturation during coronary bypass surgery: a randomized, prospective study. Anesth Analg. 2007;104:51-8

4. CAS Medical Systems. CASMED Web site. Available at: http://www.casmed. com. Accessed September 1, 2009.

5. Royston D. High-dose aprotinin therapy: a review of the first five years' experience. J Cardiothorac Vasc Anesth. 1992;6:76-100.

6. Strauch JT, Spielvogel D, Lauten A, Lansman SL, McMurtry K, Bodian CA, et al. Axillary artery cannulation: routine use in ascending aorta and aortic arch replacement. Ann Thorac Surg. 2004;78:103-8.

7. Spielvogel D, Etz CD, Silovitz D, Lansman SL, Griepp RB. Aortic arch replacement with a trifurcated graft. Ann Thorac Surg. 2007;83:791-5.

8. Etz CD, Homann TM, Rane N, Bodian CA, Di Luozzo G, Plestis KA, et al. Aortic root reconstruction with a bioprosthetic valved conduit: a consecutive series of 275 procedures. J Thorac Cardiovasc Surg. 2007;133 1455-63.

9. Slater JP, Guarino T, Stack J, Vinod K, Bustami RT, Brown JM 3rd, et al. Cerebral oxygen desaturation predicts cognitive decline and longer hospital stay after cardiac surgery. Ann Thorac Surg. 2009;87:36-44.

10. Casati A, Fanelli G, Pietropaoli P, Proietti R, Tufano R, Danelli G, et al. Continuous monitoring of cerebral oxygen saturation in elderly patients undergoing major abdominal surgery minimizes brain exposure to potential hypoxia. Anesth Analg. 2005;101:740-7.

11. Maganti M, Rao V, Armstrong S, Feindel CM, Scully HE, David TE. Redo valvular surgery in elderly patients. Ann Thorac Surg. 2009;87:521-5.

12. Chukwuemeka A, Borger MA, Ivanov J, Armstrong S, Feindel CM, David TE. Valve surgery in octogenarians: a safe option with good medium-term results. J Heart Valve Dis. 2006;15:191-6.

13. Loran DB, Hyde BR, Zwischenberger JB. Perioperative management of special populations: the geriatric patient. Surg Clin North Am. 2005;85: 1259-66. 